\title{
Concentration Characteristics of Runoff Pollutants using Statistical Techniques during a Storm: the Case Research of Driveway Site in Korea
}

\author{
Jaehwan Ahn ${ }^{\mathrm{a}}$, Seogku Kim ${ }^{\mathrm{b}}$, Sangleen Yun ${ }^{\mathrm{c}}$, Youngmin Kim ${ }^{\mathrm{d}}$, Hyundong Lee ${ }^{\mathrm{e}}$ \\ and Hyecheol $\mathrm{Oh}^{\mathrm{f}}$ \\ Korea Institute of Civil Engineering and Building Technology, Environmental \\ and Plant Engineering Research Institute, Daehwa-dong, Ilsanseo-gu, Goyang-si, \\ Gyeonggi-do, Republic of Korea \\ ajhahn@kict.re.kr, ${ }^{b}$ sgkim@kict.re.kr, ${ }^{c} l e e n 70 @ k i c t . r e . k r,{ }^{d} y . k i m @ k i c t . r e . k r$, \\ ${ }^{e}$ hdlee@kict.re.kr, ${ }^{f}$ hcoh79@kict.re.kr
}

\begin{abstract}
This research was conducted to investigate the magnitude and nature of the emission of runoff pollutants with the goal of quantifying stormwater pollutant concentrations from driveways site. A statistical summary for concentration characteristics of driveway runoff is provided based on the various analysis techniques. Runoff water qualities in temporal variation were generally higher in wet season than in dry season with a high degree of variability. The $95 \%$ confidence intervals of washed-off pollutant concentration are ranged to 82.4-141.4 $\mathrm{mgL}^{-1}$ for TSS, 53.3-87.6 $\mathrm{mgL}^{-1}$ for Turbidity, 19.0-38.7 $\mathrm{mgL}^{-1}$ for BOD, 34.0-59.2 $\mathrm{mgL}^{-1}$ for COD, 16.4-27.4 $\mathrm{mgL}^{-1}$ for DOC, 4.3-5.6 $\mathrm{mg}^{-1}$ for TN and 0.25-0.34 $\mathrm{mgL}^{-1}$ for TP, showing the high values based on the surface or lake quality standards in Korea. The first flush effect is mostly occurred within initial 30 min of storm duration. Concentrations of water quality constituents in urban stormwater are often expressed in probabilistic terms using statistics such as the mean and standard deviation and selected quintiles. Three probability distributions, weibull in TSS and Turbidity, lognormal in BOD and COD and gamma in DOC, TN and TP were fitted and the goodness-of-fit was assessed using the Anderson-Darling test. The correlation matrix of all water quality variables shows significant relationships between all parameters $(P<0.001)$ and the correlation of between TSS and Turbidity showed relatively strong positive relationship $(r=0.825)$. This research presents the concentration changes and characteristics during storm occurrence. The new concept explaining the relationship among the emission effects of runoff pollutants are suggested using statistical techniques.
\end{abstract}

Keywords: driveway, runoff, statistics, probability distributions, correlation

\section{Introduction}

Korea has made tremendous advances in the past 30 years to clean up its aquatic environment by controlling pollution from point sources. Although point source discharges have decreased in recent years, many water bodies or rivers are still impacted and are either eutrophic, with excess algae biomass and episodes of toxic algal blooms, or oxygen depletion [1]. Nonpoint sources (NPSs) are the cause of many of the problems. Especially, vehicle emissions have different pollutants such as heavy metals, oil, grease and particulates from sources such as fuels, brake pad wear and tire wear [2]. A storm event usually leads to highly polluted runoff from roadside and bridges which directly affect the water quality near the site [3]. Many studies have attempted to develop relationships among pollutant load, observed storm events, and site characteristics [4-5]. Irish et al. [6] determined that the pollutant load in highway runoff can be explained by 
causal variables measured during the rainstorm event, the antecedent dry period, and the previous rainstorm event. Wu et al. [7] used a mass balance approach that incorporated bulk precipitation, traffic contribution, and pollutant retention by vegetative filters to estimate pollutant loads from highway runoff. For some pollutants, the loads were found to be mostly associated with automobile traffic, whereas only the total suspended solids (TSS) load exhibited a strong positive trend with traffic volume during the storm [8]. During the dry periods, many types of pollutant are accumulating on the paved surface by vehicle activities. Particularly, the driveways are stormwater intensive landuses because of high imperviousness and high pollutant mass emissions from vehicles [9]. The accumulated pollutants in highways are washed-off during a rainfall event and are highly contributing on water quality of receiving water bodies [10]. The stormwater runoff from the driveways are containing various pollutants such as metals, oil \& grease and toxic chemicals originated from vehicles.

This research is performed to find pollutant characteristics in the magnitude of statistical pollutant concentrations during storm periods. Studies that determine the impact of site and event characteristics on statically analysis are rare. This research suggests a new concept to explain the relationship among the driveway runoff stormwater parameters and influent characterization effects by using statistical technique. This concept is useful to determine the quantitative analysis on the runoff water quality.

\section{Materials and Methods}

\subsection{Descriptions of Sites and Events}

Figure 1 shows the sampling location. Monitoring was performed at a roadside site in the Korean city of Goyang, to measure rainfall, runoff rate and runoff quality and to be performed by nine events during rainy days. Goyang city is geographically located between $126^{\circ} 56.5^{\prime}$ and $126^{\circ} 45^{\prime}$ in the east longitude, and $137^{\circ} 34^{\prime}$ through $137^{\circ} 41^{\prime}$ in the north latitude. The city is located in the north of South Korea, $32 \mathrm{~km}$ from Seoul, the capital city of Korea (Figure 1). Its population in 2013 was 1 million, and the city covered an area of $267.41 \mathrm{~km}^{2}$.

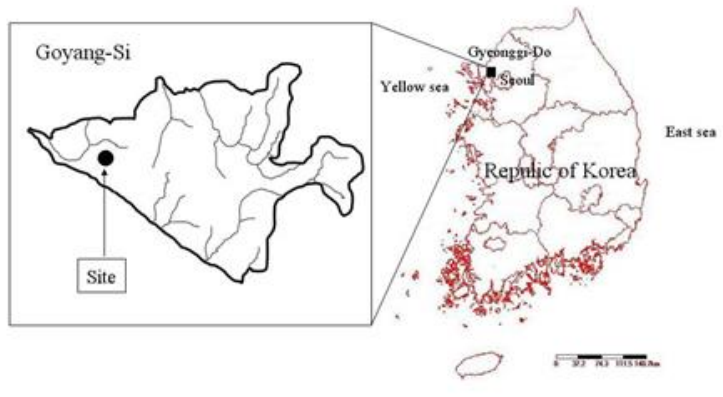

Figure 1. Monitoring and Sampling Location

Detail summaries of site and events are shown in Table 1, which includes site area, date, antecedent dry days, rainfall, storm duration, rainfall intensity, total rainfall, total runoff and runoff coefficient. The event rainfall varies from $4 \mathrm{~mm}$ to $27.5 \mathrm{~mm}$ and antecedent dry days vary from 2 to 34 days. The greatest runoff coefficient was 0.6 at event 7.

\subsection{Sampling and Analyzing Water}

Samples were collected approximately three liters using the sterilized sample bottles prior to flow into the reduction device. The bottles were prewashed and kept in the laboratory cold room prior to the storm. The water quality parameters from storm water 
runoff, including total suspended solids (TSS), turbidity (NTU), chemical oxygen demand (COD), biochemical oxygen demand (BOD), dissolved organic carbon (DOC), total nitrogen $(\mathrm{T}-\mathrm{N})$, and total phosphorus (T-P) were analyzed. Detecting the first flush required grab samples to be collect throughout the storm but especially in the early runoff period. Grab samples can be collected manually. The manual sampling provided greater flexibility, allowing larger sample volumes to be collected as well as special samples using different bottles. The first sample was collected at the very beginning of runoff and five grab samples were collected in the first hour of runoff in order to catch the first flush phenomenon. The additional samples were collected each hour until the end of runoff per event.

The samples were transported to the laboratory for analysis. All collected samples were analyzed by standard methods [11]. In all cases, samples were collected from a free waterfall. The bottles were then transported to the laboratory after collection and refrigerated at $4^{\circ} \mathrm{C}$ until analyzed. After being arrived at the laboratory, the samples were mixed and divided into sub samples for different analysis.

Table 1. Event Table for Monitoring Location

\begin{tabular}{|c|c|c|c|c|c|c|c|c|}
\hline Event & $\begin{array}{l}\text { Area } \\
\left(\mathrm{m}^{2}\right)\end{array}$ & $\begin{array}{c}\text { Antecedent } \\
\text { Dry Day } \\
\text { (days) }\end{array}$ & $\begin{array}{l}\text { Total } \\
\text { Rainfall } \\
(\mathrm{mm})\end{array}$ & $\begin{array}{l}\text { Runoff } \\
\text { Duration } \\
\quad(\mathrm{hr})\end{array}$ & $\begin{array}{l}\text { Rainfall } \\
\text { Intensity } \\
(\mathrm{mm} / \mathrm{hr})\end{array}$ & $\begin{array}{c}\text { Total } \\
\text { Rainfall } \\
\left(\mathrm{m}^{3}\right)\end{array}$ & $\begin{array}{c}\text { Total } \\
\text { Runoff } \\
\left(\mathrm{m}^{3}\right)\end{array}$ & $\begin{array}{l}\text { Runoff } \\
\text { Coeff. }\end{array}$ \\
\hline $\begin{array}{r}\text { Ev } \\
\text { ent } 1\end{array}$ & $\begin{array}{c}5 \\
00^{5}\end{array}$ & 8 & 4 & 3 & 1.3 & 20 & 8 & 38. \\
\hline $\begin{array}{r}\text { Ev } \\
\text { ent } 2\end{array}$ & $0^{5}$ & 34 & 5 & 4 & 1.3 & 25 & 13 & $\begin{array}{c}0 . \\
50\end{array}$ \\
\hline $\begin{array}{r}\text { Ev } \\
\text { ent } 3\end{array}$ & ${ }_{00}^{5}$ & 12 & 5 & 4 & 1.3 & 23 & 13 & $\begin{array}{c}0 . \\
54\end{array}$ \\
\hline $\begin{array}{r}\text { Ev } \\
\text { ent } 4\end{array}$ & $00^{5}$ & 6 & 5 & 6 & 0.8 & 23 & 10 & 43. \\
\hline $\begin{array}{r}\text { Ev } \\
\text { ent } 5\end{array}$ & $\begin{array}{c}5 \\
00\end{array}$ & 2 & 28 & 14 & 2.0 & 138 & 48 & $\begin{array}{r}0 . \\
34\end{array}$ \\
\hline $\begin{array}{r}\text { Ev } \\
\text { ent } 6\end{array}$ & ${ }^{5}$ & 8 & 10 & 7 & 1.4 & 48 & 24 & $\begin{array}{r}0 . \\
51\end{array}$ \\
\hline $\begin{array}{r}\text { Ev } \\
\text { ent } 7\end{array}$ & ${ }^{5}$ & 3 & 56 & 9 & 6.2 & 280 & 169 & $\begin{array}{l}0 . \\
60\end{array}$ \\
\hline $\begin{array}{r}\text { Ev } \\
\text { ent } 8\end{array}$ & $0^{5}$ & 7 & 16 & 8 & 2.0 & 80 & 44 & 55. \\
\hline $\begin{array}{r}\text { Ev } \\
\text { ent } 9\end{array}$ & $00^{5}$ & 2 & 35 & 7 & 5.0 & 175 & 100 & $\begin{array}{r}0 . \\
57\end{array}$ \\
\hline
\end{tabular}

\subsection{Statistical Analysis}

Summary statistics and frequency distributions were calculated to address the distributional and statistical characteristics of stormwater runoff quality. Statistical calculations were achieved using Minitab Release 12.2 and SAS Release 8.2 for Windows. Summary statistics were calculated for each constituent, which include information such as the total number of data, minimum and maximum detected values, mean, and standard deviation. The distributions of runoff quality data for each constituent were evaluated for approximate normality prior to performing additional data analyses. Goodness-of-fit tests are used to test the hypothesis that a sample distribution is drawn from a specified distribution. The probability distributions were determined by fitting select distributions to measured data by the help of goodness-of-fit tests which were chi-square, KolmogorovSmirnov, and Anderson-Darling tests. The simulation software is used in fitting distributions, which provides values of the test statistics, and allows the user to determine the best fitting distributions. We performed Pearson's correlation analysis due to the 
correlation between water quality parameter-parameter reflects the degree to which the variables are related.

\section{Results and Discussions}

\subsection{Statistical Analysis of Driveway Runoff Water Quality Data}

The water quality parameters of total storm events monitored at driveway site during the one-year study are summarized in Table 2. Nine storm events were monitored annually at driveway site during the wet seasons (October through April) and dry seasons (March through November). Five of the most common statistical properties have been selected. These are mean, median, standard deviation, minimum and maximum, coefficient of variation (C.V), skewed, and kurtosis including the $95 \%$ confidence interval of lower and upper to the arithmetic mean.

\begin{tabular}{|c|c|c|c|c|c|c|c|c|c|c|c|}
\hline \multirow{2}{*}{ Pollutant } & \multirow{2}{*}{$\mathrm{N}$} & \multirow{2}{*}{ Mean } & \multirow{2}{*}{ Median } & \multirow{2}{*}{ Std. D } & \multirow{2}{*}{ Min } & \multirow{2}{*}{$\operatorname{Max}$} & \multirow{2}{*}{ C. $V^{\mathrm{a}}$} & \multirow{2}{*}{ Skewed } & \multirow{2}{*}{ Kurtosis } & \multicolumn{2}{|c|}{ Confidence Interval } \\
\hline & & & & & & & & & & $\begin{array}{l}95 \% \\
\text { upper }\end{array}$ & $\begin{array}{l}95 \% \\
\text { lower }\end{array}$ \\
\hline $\begin{array}{l}\text { TSS } \\
\left(\mathrm{mgL}^{-1}\right)\end{array}$ & 96 & 111.9 & 59.0 & 130.1 & N.D. ${ }^{b}$ & 650.0 & 130.1 & 2.22 & 4.63 & 141.40 & 82.40 \\
\hline $\begin{array}{l}\text { Turbidity } \\
\text { (NTU) }\end{array}$ & 96 & 70.5 & 40.4 & 84.8 & N.D. ${ }^{b}$ & 395.0 & 120.4 & 2.17 & 4.71 & 87.64 & 53.27 \\
\hline $\begin{array}{l}\text { BOD } \\
\left(\mathrm{mgL}^{-1}\right)\end{array}$ & 96 & 28.4 & 12.5 & 47.7 & 1.5 & 291.9 & 167.9 & 3.68 & 15.30 & 38.65 & 18.95 \\
\hline $\begin{array}{l}\mathrm{COD} \\
\left(\mathrm{mgL}^{-1}\right)\end{array}$ & 96 & 46.6 & 24.5 & 61.5 & 3.4 & 308.0 & 132.7 & 2.48 & 6.13 & 59.23 & 34.04 \\
\hline $\begin{array}{l}\mathrm{DOC} \\
\left(\mathrm{mgL}^{-1}\right)\end{array}$ & 96 & 1.9 & 14.7 & 26.9 & 1.9 & 184.2 & 122.1 & 3.48 & 16.20 & 27.39 & 16.39 \\
\hline $\begin{array}{l}\mathrm{T}-\mathrm{N} \\
\left(\mathrm{mgL}^{-1}\right)\end{array}$ & 96 & 4.9 & 4.2 & 3.2 & 0.7 & 19.5 & 63.7 & 1.57 & 4.10 & 5.58 & 4.27 \\
\hline $\begin{array}{l}\text { T-P } \\
\left(\mathrm{mgL}^{-1}\right)\end{array}$ & 96 & 0.29 & 0.23 & 0.22 & N.D. ${ }^{b}$ & 1.05 & 84.4 & 1.47 & 3.59 & 0.34 & 0.25 \\
\hline
\end{tabular}

Among the water quality parameters, BOD showed the most skewed with the highest level of kurtosis (a high degree of variability) and coefficient of variation (C.V). All water quality parameters had the $95 \%$ upper and lower confidence interval values to the arithmetic mean much greater than the median and the geometric mean. Also, the difference between mean and median is quite large with mean being twice as large for most parameters. This results because the storm water runoff data are non-parameters distributed in uncertainty conditions. Arithmetic mean concentration of TSS and BOD is $111.9 \mathrm{mgL}^{-1}$ and $28.4 \mathrm{mgL}^{-1}$, respectively; all exceed the Class V surface or lake quality standards by more than 4 factors.

Also, the maximum concentration of TN, TP and COD from surface runoff is 19.5 $\mathrm{mgL}^{-1}, 1.05 \mathrm{mgL}^{-1}$ and $308.0 \mathrm{mgL}^{-1}$ whereas their minimum concentration is $0.7 \mathrm{mgL}^{-1}$, N.D and $3.4 \mathrm{mgL}^{-1}$, respectively, which indicates that serious nitrogen and organic pollutant losses may happen during rainfall events in driveway event [12]. 

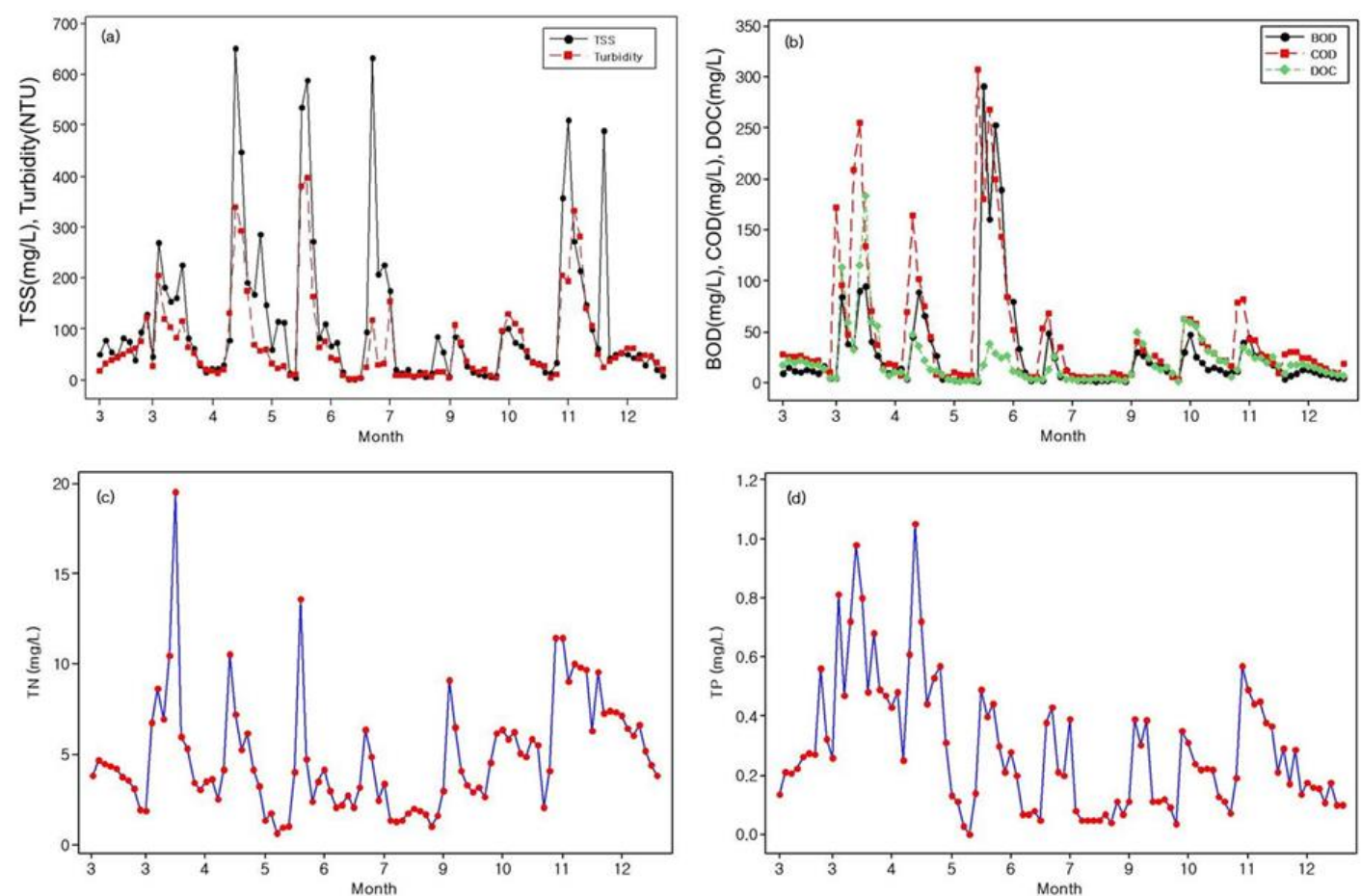

Figure 2. Box-Plot of Temproal Variations: (A) TSS and Turbdity, (B) BOD, COD, DOC, (C) TN, (D) TP in Driveway Runoff Water Quality

Also, TSS concentrations in driveway runoff observed in this study were higher than the $100 \mathrm{mgL}^{-1}$ mean concentration reported for urban runoff in the NURP study [13], and lower than the $300 \mathrm{mgL}^{-1}$ for asphalt driveways reported by Bannerman et al. [14]. TSS concentrations were significantly higher in the May than in other months. Bannerman et al. [14] identified driveways as a critical source area for phosphorus in residential watersheds. TP concentrations in runoff from asphalt driveways were lower in this study than in Bannerman's study, $0.29 \mathrm{mgL}^{-1}$ as compared to $1.16 \mathrm{mgL}^{-1}$.

\subsection{The Temporal Variation from Driveway Runoff Water Quality Data}

Seasonal different in concentrations were examined for each constituent. The greatest concentration peaks from driveway stormwater runoff quality data appeared at the beginning of May except TN (Figure 2). As shown, the dynamic runoff water quality sharply decreases with increasing storm duration because they are continuously washed off from vehicles [15]. A definition of the first emissions is the initial period of stormwater runoff during which the concentration of pollutants is substantially higher than those observed during the latter stages of the storm event. Dynamic emissions were sharply decreased in the initial 20-50-minute storm period. This phenomenon was explained by the first emission effects and can therefore be used to determine the treatment criteria. Using the time serial graphs, the first flush criteria are suggested as being the initial 5-10 $\mathrm{mm}$ accumulated rainfall (Figure 2). From Figure 2, the concentration patterns of runoff water quality parameters showed a stronger first emission and decreased according to runoff time. After the peak, the pollutant concentration rapidly reduced. The results suggest that the higher first flush is more likely to be associated with more intensive events [16].

Another primary exploratory data analysis tool, especially when difference between sample groups is of interest, is the use of grouped box and whisker plots. Examples of their use include examining different sampling seasons. These plots indicate the range and major percentile locations of the data, as shown on Figure 3. Figure 3 shows an example 
of box plots for some meaningful variables related to the quantity of runoff parameters, such as TSS, Turbidity, BOD, COD and DOC, TN and TP. The line across the box represents the median, whereas the bottom and top of the box show the locations of the first and third quartiles (Q1 and Q3) [17]. The whiskers are the lines that extend from the bottom and top of the box to the lowest and higher observations inside the region defined by $\mathrm{Q} 1-1.5(\mathrm{Q} 3-\mathrm{Q} 1)$ and $\mathrm{Q} 3+1.5(\mathrm{Q} 3-\mathrm{Q} 1)$. Individual points with values outside these limits (outliers) are plotted with asterisks. Box plots provide a visual impression of the location and shape of the underling distributions. For example, box plots with long whiskers at the top of the box (such as that for TSS in from May to July) indicate the underlying distribution is skewed toward high concentration. Box plots with large spread indicate seasonal variations of the water quality characterizations. If the 75 and 25 percentiles lines of the lines of boxes are higher or lower than the medians of other box and whisker plots, then the data groupings are likely significantly different (at least at the 95\% level). The largest ranges with in event yields for TSS, Turbidity, BOD, COD and DOC, TN and TP were in Jun, April and May (Figure 3). Significant difference in runoff parameters among temporal variations were found for all constituents. Furthermore, differences in runoff parameter concentrations were higher in the wet seasons (October through April). High turbidity is normally associated with the wet season (Jun through April) including dry season (November in this study) when surface runoff transports sediments from the soil and carries them to the stream. During the wet season the high waters are also much more turbulent and do not allow the sediments to settle on the river bed [18]. Suspended sediments can therefore travel long distances and all the tributaries also contributes to the turbidity. This is also the case here and turbidity is much higher during the wet season (Figure 3).

In the aquatic environment, nitrogen can be found in various forms: molecular nitrogen, organic nitrogen, ammonium nitrogen, nitrite and nitrate. In this study, $\mathrm{TN}$ is higher in the dry season. The reason for these generally higher concentrations can partly be explained by the fact that high waters of the wet season dilute these chemicals more. Consumption of phosphorus dose not appears to affect human health but high phosphorus levels in the water can have dramatic effects on aquatic life. Concentrations of over $0.03 \mathrm{mgL}^{-1}$ can prove excessive plant growth, increase demand of oxygen and reduce fish stock [18]. TP concentrations presented in Figure 3 and Table 2 are over $0.03 \mathrm{mgL}^{-1}$ and can be considered excessive. Phosphorous in runoff water can come from a variety of sources both point and non-point. It is associated with sewers, animal excrement, fertilizers and some detergents [19].

Using the interval graph to represent the $95 \%$ upper and lower confidence limitations to arithmetic mean, Figure 4 presented that ranges of driveway parameter concentrations were the largest in November (C.I: $316.4 \mathrm{mgL}^{-1}, 60.95 \mathrm{mgL}^{-1}$ ) (TSS), in June (C.I: 189.3 $\mathrm{mgL}^{-1}, 8.6 \mathrm{mgL}^{-1}$ ) (Turbidity), in June (C.I: $189.3 \mathrm{mgL}^{-1}, 32.1 \mathrm{mgL}^{-1}$ ) (BOD), in May (C.I: $121.2 \mathrm{mgL}^{-1}, 4.19 \mathrm{mgL}^{-1}$ ) (COD), in April (C.I: $91.6 \mathrm{mgL}^{-1}, 20.1 \mathrm{mgL}^{-1}$ ) (DOC), in April (C.I: $9.67 \mathrm{mgL}^{-1}, 3.68 \mathrm{mgL}^{-1}$ ) (TN) and in May (C.I: $0.59 \mathrm{mgL}^{-1}, 0.18 \mathrm{mgL}^{-1}$ ) (TP), respectively. 

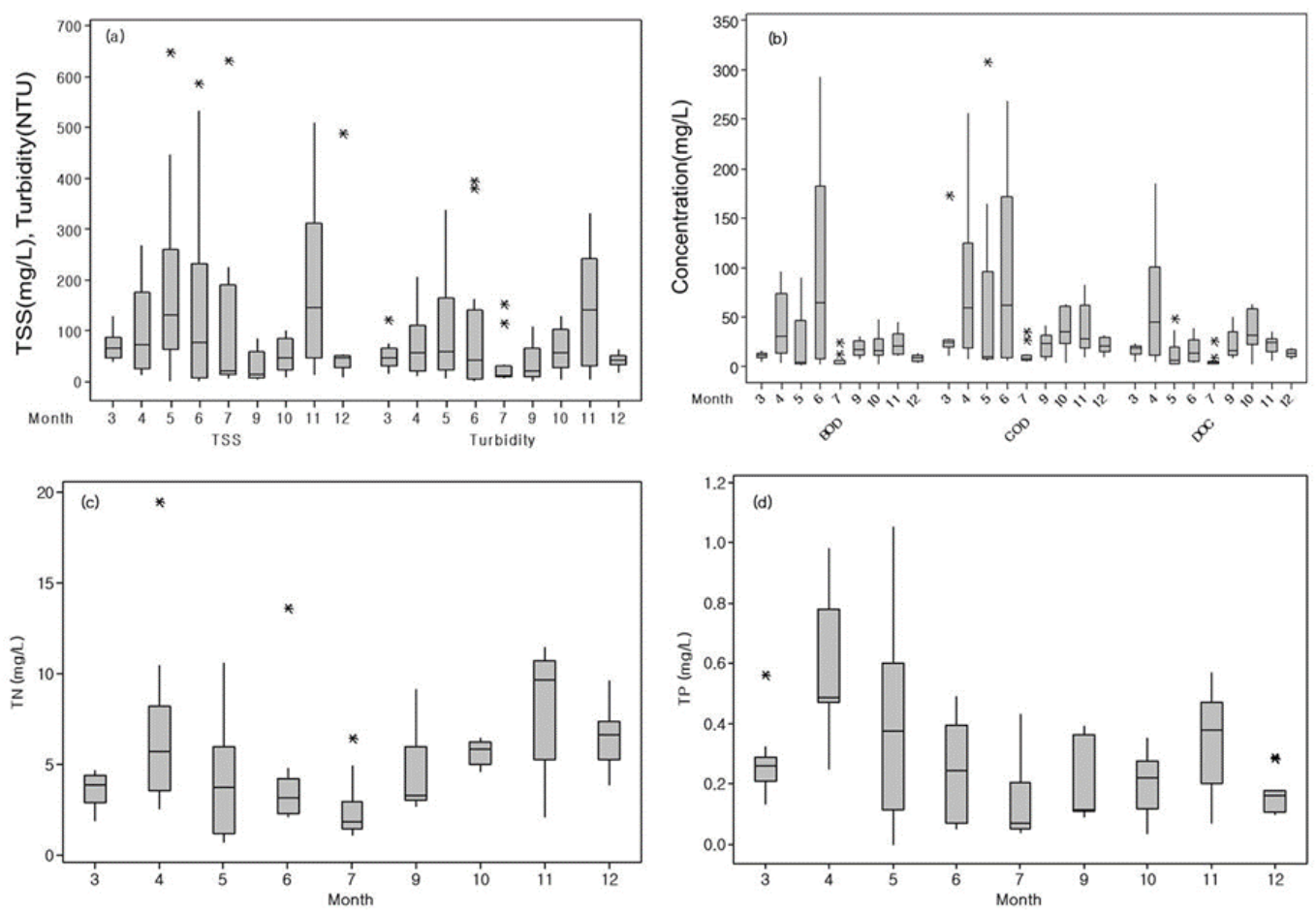

Figure 3. Box-Plot of Temproal Variations: (A) TSS and Turbdity, (B) BOD, COD, DOC, (C) TN, (D) TP in Driveway Runoff Water Quality
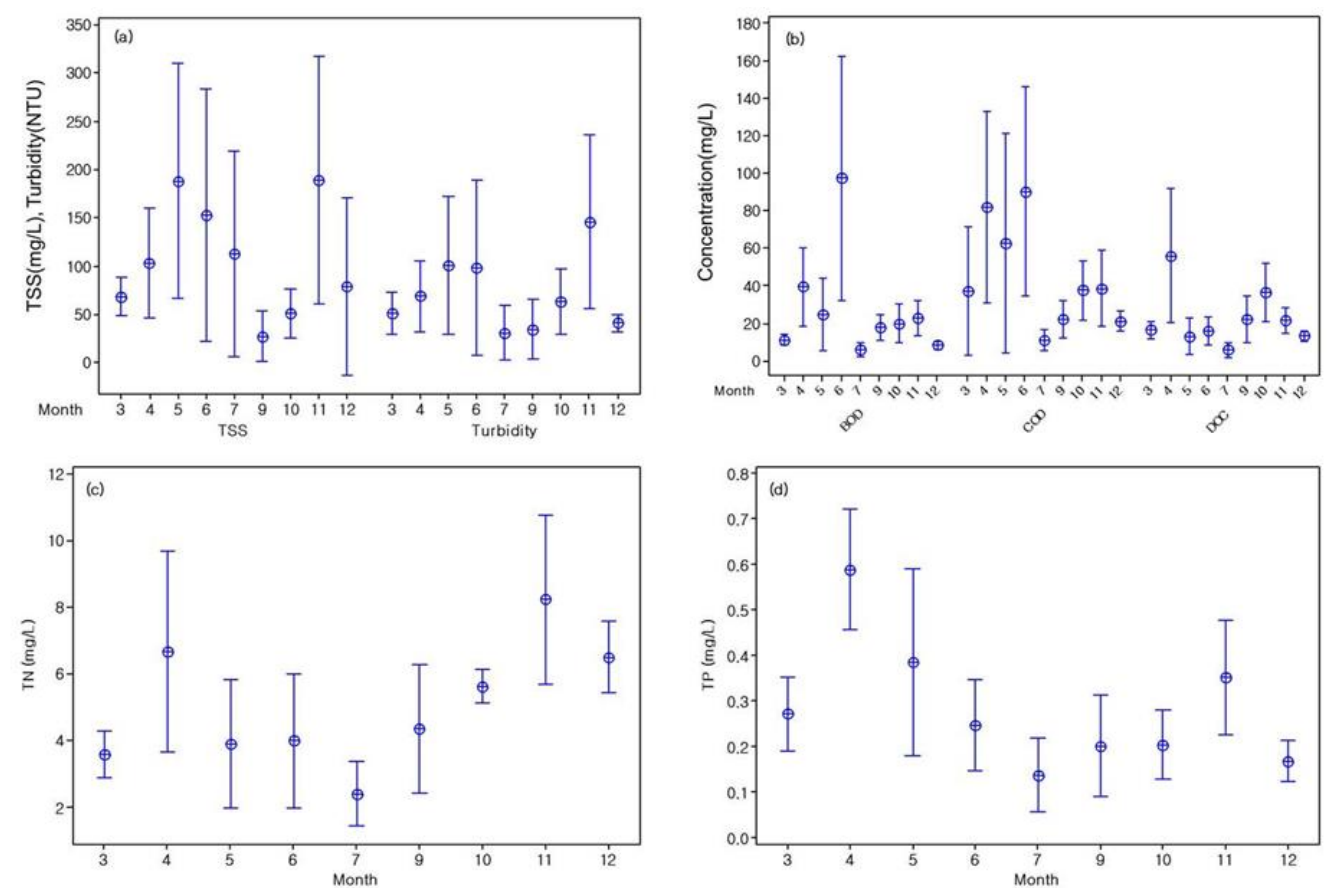

Figure 4. Interval Graph of Temproal Variations: (A) TSS and Turbdity, (B) BOD, COD, DOC, (C) TN, (D) TP in Driveway Runoff Water Quality

\subsection{Probability Uncertainty Distributions from Driveway Runoff Quality Data}

The uncertainties or variability in runoff stormwater water quality can be expressed in terms of probabilistic distributions. The probability distributions show the range of values the variable could take and the likelihood of occurrence of each value within the 
describing the probability measures associated with the range [20]. Thus, the distributions define the rule for describing the probability measures associated with the values of a random (uncertain) variable. Probability distributions may be described in their entirety as cumulative distribution functions, or by selected parameters, such as moments (e.g. mean and variance). Different distributions were produced for each uncertainty region. The Anderson-Daring statistics were used to test the goodness-of-fit of the data to uncertainty distribution. For the runoff pollutant parameters, uncertainty concentration distributions were characterized. Several types of probability distributions are shown in Table 3 and Figure 5 as both probability density functions (pdf's) and cumulative distribution functions (cdf's) in equation 1 to 3 [21].

Weibull distribution:

$$
f(x)=\frac{\left(\frac{x-L}{\beta}\right)^{\alpha-1} e^{-\frac{x-L}{\beta}}}{\Gamma(\alpha) \beta} \text { for } \mathrm{x}>\mathrm{L} \text {; with any value of } \alpha \text { and } \beta
$$

Lognormal distribution:

$$
\begin{aligned}
& f(x)=\frac{1}{x \sqrt{2 \pi} \ln (\sigma)} e^{-\frac{[\ln (x)-\ln (\mu)]^{2}}{2[\ln (\sigma)]^{2}}} \\
& \text { mean }=\mu+\frac{\sigma^{2}}{2} \quad \text { for } \mathrm{x}>0 ; \mathrm{u}>0 \text { and } \sigma<0 \\
& \text { variance }=\left(\sigma^{2}+\mu^{2}\right)\left(\mu^{2}-1\right)
\end{aligned}
$$

Gamma distribution:

$$
f(x)=\frac{\beta}{\alpha}\left[\frac{x-L}{\alpha}\right]^{\beta-1} e^{-\left(\frac{x-L}{\alpha}\right)^{\beta}} \text { for } \mathrm{x} \geq \mathrm{L} ; \text { with any value of } \alpha \text { and } \beta
$$

As stated earlier, the probability uncertainty distributions have different parameter coefficients according to their distribution characterizations, which Location (L), Scale $(\alpha)$, Shape $(\beta)$, Mean $(\mu)$, and Stad. D $(\sigma)$. All coefficients have a different meaning such as runoff characterizations. The pdf is a graphical means of representing the relative likelihood or frequency with which values of a variable may be obtained. The weibull in TSS and Turbidity, lognormal in BOD and COD and gamma in DOC, TN and TP distributions are selected as there are strong theoretical and empirical considerations to assume these distributions a priori for many physical entities. Example, in the case of lognormal distribution, the maximum absolute distance between the data and the hypothesized distribution is calculated to test the conformance of the two cumulative distribution functions.

Based on the probability density functions (pdf's) and cumulative distribution functions (cdf's) of runoff pollutants, 95\% percentile values of TSS, Turbidity, BOD,

\begin{tabular}{|c|c|c|c|c|c|c|c|c|}
\hline \multirow{2}{*}{$\begin{array}{l}\text { Paramet } \\
\text { ers }\end{array}$} & \multirow{2}{*}{$\begin{array}{l}\text { Distributi } \\
\text { ons }\end{array}$} & \multirow{2}{*}{ Parameters ${ }^{a}$} & \multicolumn{6}{|c|}{ Percentiles } \\
\hline & & & $5 \%$ & $25 \%$ & $50 \%$ & $75 \%$ & $90 \%$ & $95 \%$ \\
\hline $\begin{array}{l}\text { TSS } \\
\left(\mathrm{mgL}^{-1}\right)\end{array}$ & Weibull & $\begin{array}{l}-0.49^{\mathrm{b}}, 7.35^{\mathrm{c}}, \\
0.78^{\mathrm{d}}\end{array}$ & 1.67 & 19.23 & 60.37 & 147.47 & 283.01 & 396.72 \\
\hline
\end{tabular}
COD, DOC, TN and TP are $396.7 \mathrm{mgL}^{-1}, 238.3 \mathrm{mgL}^{-1}, 93.6 \mathrm{mgL}^{-1}, 145.8 \mathrm{mgL}^{-1}, 66.3$ $\mathrm{mgL}^{-1}, 11.0 \mathrm{mgL}^{-1}$ and $0.72 \mathrm{mgL}^{-1}$, respectively.

Table 3. The Probability Uncertainty Analysis on the Concentration Distribution of Runoff Water Quality Parameters 


\begin{tabular}{|c|c|c|c|c|c|c|c|c|}
\hline $\begin{array}{l}\text { Turbidit } \\
\text { y } \\
\text { (NTU) }\end{array}$ & Weibull & $\begin{array}{l}-0.34^{\mathrm{b}}, 64.5^{\mathrm{c}}, \\
0.84^{\mathrm{d}}\end{array}$ & 1.53 & 14.28 & 41.36 & 94.91 & 174.05 & 238.30 \\
\hline $\begin{array}{l}\text { BOD } \\
\left(\mathrm{mgL}^{-1}\right)\end{array}$ & $\begin{array}{l}\text { Lognorm } \\
\text { al }\end{array}$ & $26.82^{\mathrm{e}}, 47.51^{\mathrm{f}}$ & 1.86 & 5.90 & 13.18 & 29.45 & 60.72 & 93.61 \\
\hline $\begin{array}{l}\mathrm{COD} \\
\left(\mathrm{mgL}^{-1}\right)\end{array}$ & $\begin{array}{l}\text { Lognorm } \\
\text { al }\end{array}$ & $44.41^{\mathrm{e}}, 65.26^{\mathrm{f}}$ & 4.28 & 12.12 & 24.99 & 51.51 & 98.78 & 145.84 \\
\hline $\begin{array}{l}\mathrm{DOC} \\
\left(\mathrm{mgL}^{-1}\right)\end{array}$ & Gamma & $\begin{array}{l}1.71^{\mathrm{b}}, 24.53^{\mathrm{c}}, \\
0.82^{\mathrm{d}}\end{array}$ & 2.30 & 6.31 & 14.43 & 29.47 & 50.25 & 66.29 \\
\hline $\begin{array}{l}\mathrm{T}-\mathrm{N} \\
\left(\mathrm{mgL}^{-1}\right)\end{array}$ & Gamma & $0.5^{\mathrm{b}}, 2.19^{\mathrm{c}}, 2.02^{\mathrm{d}}$ & 1.30 & 2.64 & 4.23 & 6.46 & 9.09 & 10.97 \\
\hline $\begin{array}{l}\text { T-P } \\
\left(\mathrm{mgL}^{-1}\right)\end{array}$ & Gamma & $\begin{array}{l}-0.01^{\mathrm{b}}, 0.17^{\mathrm{c}}, \\
1.76^{\mathrm{d}}\end{array}$ & 0.04 & 0.13 & 0.24 & 0.39 & 0.58 & 0.72 \\
\hline
\end{tabular}

In many cases, these distributions between chemical-specific and environmental properties are not completely straightforward: many parameters depend on both properties of the chemical as well as on the environment (e.g. paved road conditions, weather). Also, the graph of the distribution of pollutant load represented the receptor effects of the total pollutant loads that washed off from the roadside during runoff event periods. Considering the amounts of runoff pollutants, all runoff pollutants with $95 \%$ percentiles values may affect the aquatic life in river or ecosystem. Water quality guidelines or standards are generally specified as numerical values of constituent concentrations to be met. The degree of compliance depends on the nature of such requirements, which range from (mandatory) standards to guideline (recommended) values, with "softer" requirements, and where failure to comply does not have dramatic consequences, the probability of compliance may be somewhat relaxed.

Again, this problem may be addressed by fitting a probability distribution to the data; in some cases, this may require some extrapolation of the fitted distribution. To assess the reliability of the fitted distribution, levels of confidence are sometimes used. One example is the compliance with bacteriological data guidelines in recreational waters. House [22] reported a proposed guideline of this nature specified as 126 Escherichia coli/100ml, and the probabilities of compliance equal to 82,90 and $95 \%$ for light, moderate, and frequent body contact, respectively. The determination of such compliance would be based on fitting a probability distribution to the local measurements [23]. 

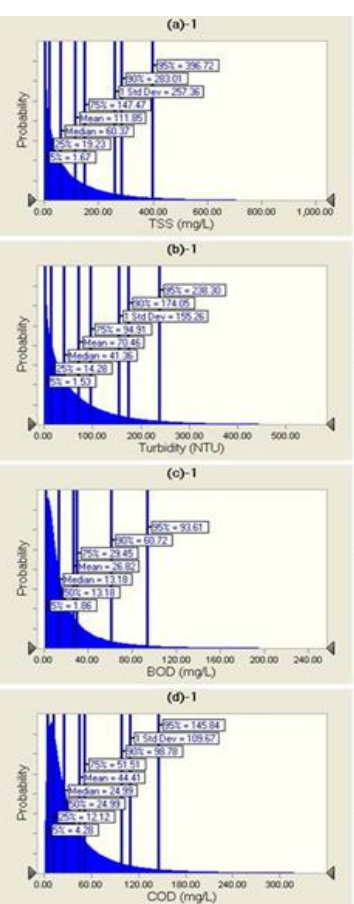

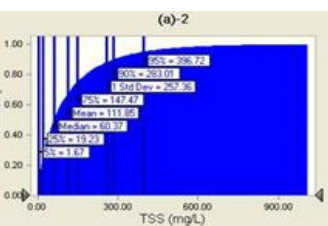

Tstim

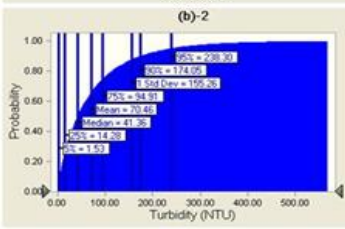

(c)-2

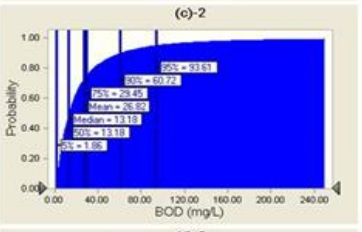

(ब) -2

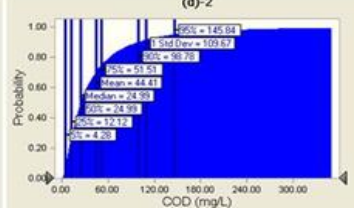

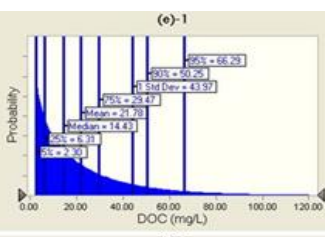

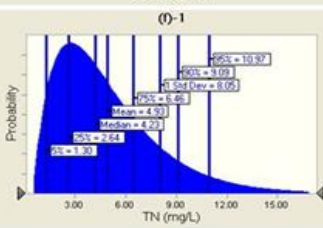

(9)- 1
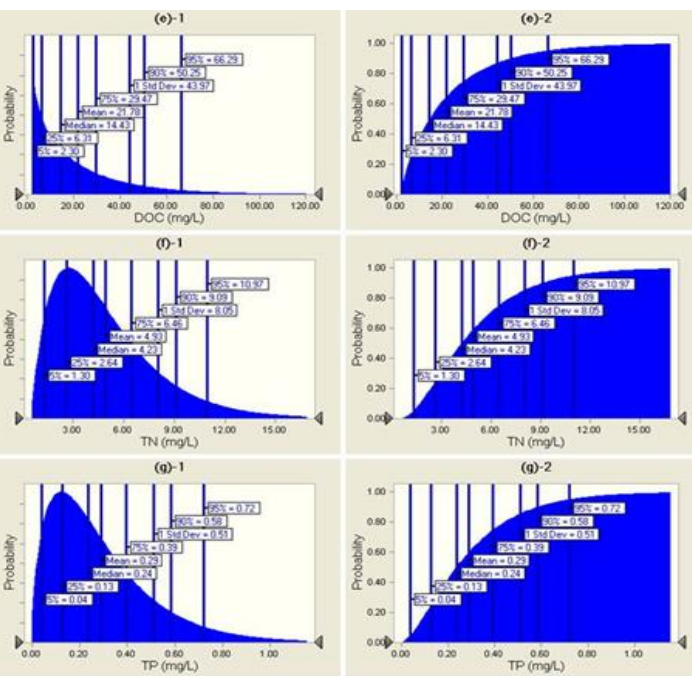

\section{Figure 5. The Uncertaitny Concentration Distributions of Runoff Stormwater Parameters: (A) Left Graph; Probability Density Fuctions (Pdfs), (B) Right Graph; Cumulative Density Functions (Cdfs)}

\subsection{Correlation Analysis from Driveway Runoff Quality Data}

In probability theory and statistics, correlation, (often measured as a correlation coefficient), indicates the strength and direction of a linear relationship between two random variables. In general statistical usage, correlation or co-relation refers to the departure of two variables from independence. In this broad sense there are several coefficients, measuring the degree of correlation, adapted to the nature of data. The Pearson coefficient is also known as the "sample correlation coefficient". The Pearson correlation coefficient is then the best estimate of the correlation of $\mathrm{X}$ and $\mathrm{Y}$. The Pearson correlation coefficient (r) is written [24]:

$$
r=\frac{\sum(X-\bar{X})(Y-\bar{Y})}{\sqrt{\sum(X-\bar{X})^{2} \sum(Y-\bar{Y})^{2}}}
$$

Data in Table 4 provide the correlation of runoff pollutant parameters obtained from the Pearson correlation equation. The correlation matrix of all water quality variables shows significant relationships between all parameters $(\mathrm{P}<0.001)$. Among the relationship, the correlation of between TSS and Turbidity showed relatively strong positive relationship $(\mathrm{r}=0.825)$. The moderate positive correlations were also observed among parameters associated with Turbidity-TP $(\mathrm{r}=0.786)$, DOC-TP $(\mathrm{r}=0.778)$, BOD-TP $(\mathrm{r}=0.738)$, Turbidity-BOD ( $\mathrm{r}=0.731)$, Turbidity-DOC $(\mathrm{r}=0.724)$, TSS-TP $(\mathrm{r}=0.720)$, Turbidity-TN ( $\mathrm{r}=0.714)$, COD-DOC ( $\mathrm{r}=0.710)$, and BOD-COD $(\mathrm{r}=0.7)$, respectively.

Table 4. Pearson's Correlation Coefficient Matrix For Runoff Water Quality Parameters

\begin{tabular}{llllllll}
\hline & TSS & Turbidity & BOD & COD & DOC & TN & TP \\
\hline TSS & 1 & & & & & & \\
Turbidity & 0.825 & 1 & & & & & \\
\hline
\end{tabular}




\begin{tabular}{llllllll}
\hline BOD & 0.590 & 0.731 & 1 & & & & \\
COD & 0.478 & 0.582 & 0.700 & 1 & & & \\
DOC & 0.485 & 0.724 & 0.485 & 0.710 & 1 & & \\
TN & 0.553 & 0.714 & 0.624 & 0.533 & 0.670 & 1 & \\
TP & 0.720 & 0.786 & 0.738 & 0.601 & 0.778 & 0.610 & 1 \\
\hline
\end{tabular}

Note: All significant at $99 \%$

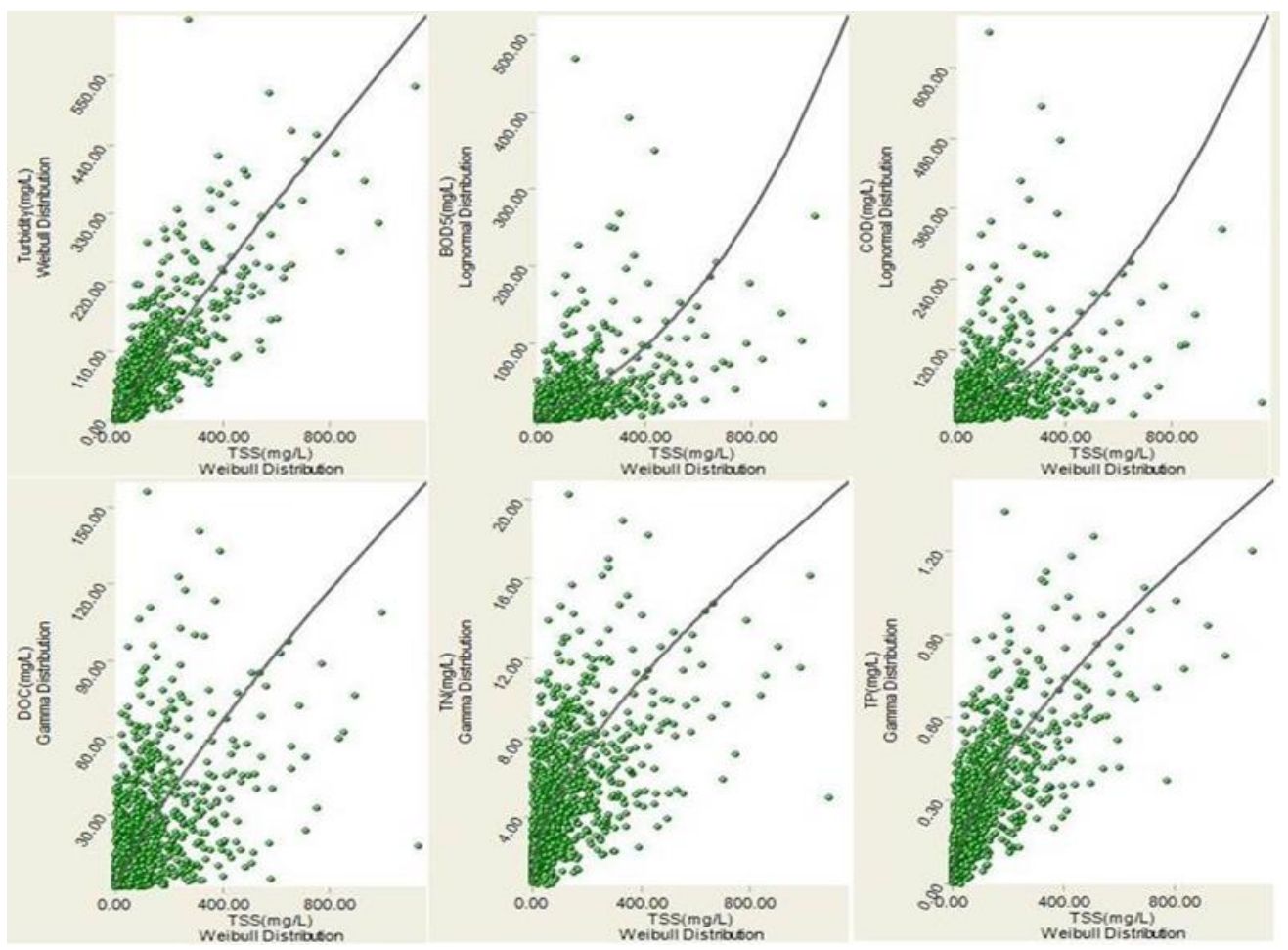

Figure 6. The Relatioship of Total Suspended Soild (TSS) and Other Runoff Parameters Based on the Pearson Correalation Listed in Table 4

Especially, the main parameters that contribute to the majority of water quality problems in runoff pollutants are: Suspended solids because it is a general indicator of pollution, COD and BOD because they supply a relative indication of the organic pollution. Besides, they are assumed as a reference parameter in many mathematical models simulating the pollutants dynamics during storm water runoff [25]. TSS had medium correlation with $\mathrm{COD}$ and $\mathrm{TN}$ with a medium value $(>0.478,>0.553)$ of the

correlation coefficient, which indicates that a close relationship between soil losses and nitrogen discharge from urban surface runoff. However, from these results on the relationship of TSS and BOD and COD, the qualitative description of the strength was weak positive, respectively. From a management perspective, structural surface improvement measures such as detention basins or sediment traps would be effective in removing most of the nutrient pollutants and organic pollutants in the urban surface runoff discharge from the driveway. 


\section{Conclusion}

Water quality parameters were monitored on a consistent basis at driveway site in Goyang city. This paper summarized and analyzed the characteristics of washed-off pollutants using various statistical techniques from driveway site in Korea. The following conclusions can be made:

1) In the emission characterization of runoff water quality, BOD has largest variability based on the coefficient of variation (C.V) and most of water quality parameters have arithmetic mean much greater than the median due to characterizations of uncertainty distribution of each water quality parameter

2) The mean concentrations of TSS, BOD, COD, TN and TP all exceed the Class V surface and lake quality standards in Korea.

3) Dynamic emissions of non-point pollutants in driveway site were sharply decreased in the initial 20-50 minute storm period because of the initial $5-10 \mathrm{~mm}$ accumulated rainfall by the first flush phenomenon.

4) Significant difference of temporal variations in runoff water quality parameters were found and were higher in the wet seasons (October through April).

5) With the uncertainties or variability analysis in runoff stormwater water quality using the goodness-of-fit of the data to uncertainty distribution, the weibull in TSS and Turbidity, lognormal in BOD and COD and gamma in DOC, TN and TP distributions are determined.

6) Based on the cumulative distribution functions (cdf's) of runoff pollutants, $95 \%$ percentile values of TSS, Turbidity, BOD, COD, DOC, TN and TP are $396.7 \mathrm{mgL}^{-1}$, $238.3 \mathrm{mgL}^{-1}, 93.6 \mathrm{mgL}^{-1}, 145.8 \mathrm{mgL}^{-1}, 66.3 \mathrm{mgL}^{-1}, 11.0 \mathrm{mgL}^{-1}$ and $0.72 \mathrm{mgL}^{-1}$, respectively.

7) The strongest correlations were observed among parameters associated with TSSturbidity ( $\mathrm{r}=0.825)$ and the moderate positive correlations were also observed among parameters associated with Turbidity-TP $(\mathrm{r}=0.786)$, DOC-TP $(\mathrm{r}=0.778)$, BOD-TP $(\mathrm{r}=0.738)$, Turbidity-BOD $(\mathrm{r}=0.731)$, Turbidity-DOC $(\mathrm{r}=0.724)$, TSS-TP $(\mathrm{r}=0.720)$, Turbidity-TN ( $\mathrm{r}=0.714)$, COD-DOC ( $\mathrm{r}=0.710)$, and BOD-COD ( $\mathrm{r}=0.7)$, respectively.

Although the assessment and analysis of driveway runoff water quality using various statistical techniques were applied in this study, it would be impossible to generalize these results to other driveway runoff locations in Korea, since runoff water quality parameters may vary according to the geographic area, with the potential for the presence of other runoff water contaminants may also exist at other sites. Also, as described above, although the monitoring, concentration assessments for runoff water quality parameters in driveway sites were carried out, given the large variances between sampling sites due to the emission characteristics of runoff pollutants, no conclusions could be drawn that the average levels found in this study would be representative of the entire country. However, a streamlined process and guidelines for future driveway runoff assessment have been provided, with insights that help both the analysts and decision makers ask the right questions at non-point sites in Korea have been generated.

\section{Acknowledgments}

This research was financially supported by Korea Institute of Civil Engineering and Building Technology (KICT), project No. 2015-0123.

\section{References}

[1] L.H. Kim, S.O. Ko, S. Jeong and J. Yoon, "Characteristics of washed-off pollutants and dynamic EMCs in parking lots and bridges during a storm", Science of The Total Environment, vol. 376, no. 1-3, (2007), pp. 178-184. 
[2] J. German and G. Svensson, "Metal content and particle size distribution of street sediments and street sweeping waste", Water Science and Technology, vol. 46, no. 6-7, (2007), pp. 191198.

[3] L.B. Irish, M.E. Barrett, J.F. Malina and R.J. Charbeneau, "Use of regression models for analyzing highway storm-water loads", Journal of Environmental Engineering, vol. 124, (1998), pp. 987-993.

[4] J. S. Wu, C. J. Allan, W. L. Saunders and J. B. Evett, "Characterization and pollutant loading estimation for highway runoff”, Journal of Environmental Engineering, vol. 124, (1998), pp. 584-592.

[5] G.W. Characklis and M.R. Wiesner, "Particles, metals, and water quality in runoff from large urban watershed", Journal of Environmental Engineering, vol. 123, (1997), pp. 753-759.

[6] [6] V. A. Tsihrintzis and R. Hamid, "Modeling and management of urban stormwater runoff quality: A review", Water Resources Management, vol. 11, (1997), pp. 137-164.

[7] APHA/AWWA/WPCF, "Standard methods for the examination of water and wastewater. 20th American Public Health Association/ American Water Works Association/ Water Pollution Control Federation", Washington, DC, USA, (1998), p. 1268.

[8] Y. Yuan and R.L. Bingner, "Assessment of best management practices for water quality improvement for the deep hollow watershed in Mississippi Delta MSEA project using AGNPS", Channel \& Watershed Processes Research Unit National Sedimentation Laboratory Oxford, (2002), pp. 28-34.

[9] J.K. Gilberta and J.C. Clausenb, "Stormwater runoff quality and quantity from asphalt, paver, and crushed stone driveways in Connecticut", Water Research, vol. 40, (2006), pp. 826-832.

[10] R.T. Bannerman, D.W. Owens, R.B. Dodds and N.J. Hornewer, "Sources of pollutants in Wisconsin stormwater", Water Science Technology, vol. 28, no. 3-5, (1993), pp. 241-259.

[11] M. Kayhanian, C. Suverkropp, A. Ruby and K. Tsay, "Characterization and prediction of highway runoff constituent event mean concentration", Journal of Environmental Management, vol. 85, no. 2, (2007), pp. 279-295.

[12] P.L. Brezonik and T.H. Stadelmann, "Analysis and predictive models of stormwater runoff volumes, loads, and pollutant concentrations from watersheds in the Twin Cities metropolitan area, Minnesota, USA”, Water Research, vol. 36, no. 7, (2002), pp. 1743-1757.

[13] M. Vega, R. Pardo, E. Barrado and L. Debán, "Assessment of seasonal and polluting effects on the quality of river water by exploratory data analysis", Water Research, vol. 32, no. 12, (1998), pp. 3581-3592.

[14] J.H. Lee and K.W. Bang, "Characterization of urban stormwater runoff”, Water Research, vol. 34, no. 6, (2000), pp. 1773-1780.

[15] P. Göbel, C. Dierkes and W.G. Coldewey, "Storm water runoff concentration matrix for urban areas", Journal of Contaminant Hydrology, vol. 91, no. 1-2, (2007), pp. 26-42.

[16] M.A. Van Buren, W.E. Watt and J. Marsale, "Application of the log-normal and normal distributions to stormwater quality parameters", Water Research, vol. 31, no. 1, (1997), pp. 95-104.

[17] I.H. Cho and S.W. Chang, "The potential and realistic hazards after a solar-driven chemical treatment of benzene using a health risk assessment at a gas station site in Korea", Journal of Environmental Science and Health Part A, vol. 43, (2008), pp. 86-97.

[18] M.A. House, J.B. Ellis, E.E. Herricks, T. Hvitved-Jacobsen, J. Seager, L. Lijklema, H. Aalderink and L.T. Clifforde, "Urban drainage impacts on receiving water quality", Water Science and Technology, vol. 27, no. 12, (1993), pp. 117-158.

[19] S.J. Wu, Y.K. Tung and J.H. Yang, "Stochastic generation of hourly rainstorm events", Stoch Environ Res Risk Assess, vol. 21, (2006), pp. 195-212.

[20] G. Manache and C.S. Melching, "Identification of reliable regression- and correlation-based sensitivity measures for importance ranking of water-quality model parameters", Environmental Modelling \& Software, vol. 23, (2008), pp. 549-562.

[21] J. Chen and B.J. Adams, "A derived probability distribution approach to stormwater quality modeling”, Advances in Water Resources, vol. 30, no. 1, (2007), pp. 80-100. 


\section{Authors}
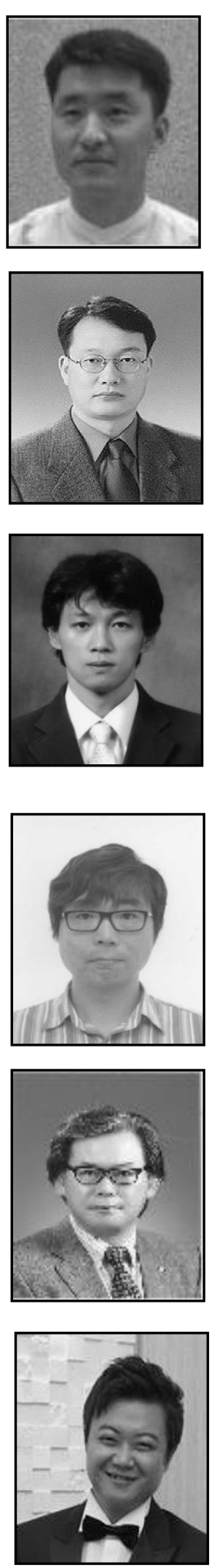

\section{Jaehwan Ahn}

Major : Environmental Engineering

Degree : Ph.D. / Research Fellow

Affiliation : Korea Institute of Civil Engineering and Building Technology (KICT)

\section{Seogku Kim}

Major : Environmental Engineering Degree : Ph.D. / Senior Research Fellow

Affiliation : Korea Institute of Civil Engineering and Building Technology (KICT)

\section{Sangleen Yun}

Major : Environmental Engineering

Degree : Ph.D. / Senior Researcher

Affiliation : Korea Institute of Civil Engineering and Building Technology (KICT)

\section{Youngmin Kim}

Major : Environmental Engineering

Degree : Ph.D. / Researcher

Affiliation : Korea Institute of Civil Engineering and Building Technology (KICT)

\section{Hyundong Lee}

Major : Environmental Engineering

Degree : Ph.D. / Senior Research Fellow

Affiliation : Korea Institute of Civil Engineering and Building Technology (KICT)

\section{Hyecheol Oh}

Major : Environmental Engineering

Degree : Ph.D. / Researcher

Affiliation : Korea Institute of Civil Engineering and Building Technology (KICT) 